\title{
Commitment of Cultural Minorities in Organizations: Effects of Leadership and Pressure to Conform
}

\author{
Joyce Rupert • Karen A. Jehn • \\ Marloes L. van Engen · Renée S. M. de Reuver
}

Published online: 1 September 2009

(c) The Author(s) 2009. This article is published with open access at Springerlink.com

\begin{abstract}
Purpose In this study, we investigated the commitment of cultural minorities and majorities in organizations. We examined how contextual factors, such as pressure to conform and leadership styles, affect the commitment of minority and majority members.

Design/Methodology/Approach A field study was conducted on 107 employees in a large multinational corporation.

Findings We hypothesize and found that cultural minorities felt more committed to the organization than majority members, thereby challenging the existing theoretical view that cultural minorities will feel less committed. We also found that organizational pressure to conform and effective leadership increased the commitment of minorities.

Implications Our findings indicate that organizational leaders and researchers should not only focus on increasing and maintaining the commitment of minority members, but should also consider how majority members react to cultural socialization and integration processes. The commitment of minority members can be further enhanced by effective leadership.

Originality/Value In this study, we challenge the existing theoretical view based on similarity attraction theory and relational demography theory, that cultural minorities
\end{abstract}

Received and reviewed by former editor, George Neuman.

J. Rupert $(\bowtie) \cdot$ K. A. Jehn

Department of Social and Organizational Psychology, Leiden

University, Wassenaarseweg 52, 2300, RB, Leiden,

The Netherlands

e-mail: JRupert@fsw.leidenuniv.nl

M. L. van Engen - R. S. M. de Reuver

Tilburg University, Tilburg, The Netherlands would feel less committed to the organization. Past research has mainly focused on minority groups, thereby ignoring the reaction of the majority to socialization processes. In this study, we show that cultural minorities can be more committed than majority members in organizations. Therefore, the perceptions of cultural majority members of socialization processes should also be considered in research on cultural diversity and acculturation.

Keywords Cultural minorities - Socialization · Organizational commitment · Leadership .

Pressure to conform $\cdot$ Acculturation

In the last decade societies and organizations have become increasingly multicultural and growing attention is being paid by business practitioners as well as scientists to the integration of cultural minorities into organizations (Chemers et al. 1995; Cox 1993). Organizations are becoming increasingly aware of the impact of diversity in the workplace and the need to manage this diversity to sustain their competitive advantage (Jehn and Bezrukova 2004; Thomas and Ely 1996). Past research on the impact of diversity in the workplace has mainly focused on the effects of team diversity on group processes, such as conflict and information processing, on workgroup and individual outcomes like performance, commitment, satisfaction, and turnover (e.g., Ely and Thomas 2001; Jehn et al. 1999; Pelled et al. 1999). This past research has mixed results, some studies indicating that diversity can increase creativity and problem solving, others showing that diversity can lead to conflict and decreased performance (for reviews and metaanalyses see Jackson et al. 2003; Mannix and Neale 2005; Stewart 2006; Webber and Donahue 2001; Williams and O'Reilly 1998). However, research on cultural minorities 
and the integration of cultural minority members with the majority group in organizations is comparatively lacking (c.f. Williams and O'Reilly 1998; c.f. Jackson et al. 1992). Also in research on heterogeneity and relational demography, cultural diversity is examined less extensively than other demographic variables, such as gender, age, and tenure (c.f. Williams and O'Reilly 1998).

In this study of 107 employees in a large multinational in the field of electronics, located in the Netherlands, we use a social identity and acculturation framework to examine the effect of cultural diversity on organizational outcomes. Specifically, we focus on differences in organizational commitment of cultural majorities versus cultural minorities, the latest defined as individuals that were born in or that have at least one parent born in a country other than the country of the majority group (Arends-Tóth and Van de Vijver 2001). These differences in organizational commitment can have a tremendous impact on organizational outcomes in turn, as organizational commitment has behavioral consequences that are of high importance to organizations. For example, Mathieu and Zajacs' (1990) and Riketta and Van Dicks' (in press) metaanalyses showed that committed employees are more motivated and loyal to the organization, more satisfied with the organization, are less likely to leave the organization, and under most circumstances will perform better than employees who are not committed. Therefore, organizational commitment is an important predictor of positive organizational outcomes and an important condition to facilitate a successful integration of minority members into the organization and, in the end, in society as a whole.

As this study includes both cultural minorities as majority members in an organization, the study of differences in organizational commitment is particularly interesting. Commitment to an organization may be shaped by the socialization process, in which the organization teaches employees about values and norms (Allen and Meyer 1990b; Caldwell et al. 1990). This socialization experience may affect the commitment of the individual toward the organization (Buchanan 1974; Louis 1980). Individuals with different cultural backgrounds often have different value systems acquired from varying socialization experiences (Dougherty 1992), which can lead to different conventions regarding social relationships at work and task accomplishment (Jehn et al. 1999; Von Glinow et al. 2004). Therefore, we expect that feelings of organizational commitment will be different for cultural minorities than for cultural majority members.

Furthermore, we also propose two moderators that we believe are important to explain the relationship between cultural dissimilarity and commitment. First, we will study whether commitment to the organization will be facilitated through strong socialization practices in the organization.
More specifically, we will study the moderating impact of pressure to conform to the organizational norms as a measure of socialization practices. A strong corporate culture may hamper the socialization of employees from cultural minority groups (e.g., Benschop 2001). Secondly, we will study the impact of leadership styles on the organizational commitment of minority versus majority members. Leaders have shown to influence employee outcomes, such as follower's job satisfaction and work motivation (Judge and Piccolo 2004), which are likely to influence employee's organizational commitment as well. We propose that since minority members have different socializations than majority members, leadership styles will differentially impact various types of organizational commitment for these two groups.

\section{Cultural Minorities and Organizational Commitment}

To our knowledge, there is hardly any research yet on the relationship between cultural dissimilarity and organizational commitment (for exceptions see Riordan and Shore 1997; Tsui et al. 1992). Research on dissimilarity and relational demography often draws on social identity theory and similarity-attraction theory to argue a negative relationship between demographic dissimilarity and organizational outcomes (e.g., Chatman et al. 1998; Chattopadhyay 1999; Riordan 2000; Tsui et al. 1992; Tsui and O'Reilly 1989). Similarity-attraction theory states that individuals feel attracted to people who are similar to themselves, which leads to more frequent communication and higher social integration within a group (Berscheid and Walster 1987; Byrne 1971). Consequently, dissimilarity will lead to lower integration and commitment to the group. In general, social identity theory is congruent with the similarityattraction paradigm, proposing that individuals identify with several social groups from which they derive a positive social identity and build self-esteem (Tajfel and Turner 1979, 1986; Turner 1982). An individual who is demographically dissimilar to the majority of other organizational members, may perceive that his or her identity is being threatened and will have an increased awareness of the characteristics of his or her own demographically dissimilar group (Riordan and Shore 1997). Riordan and Shore (1997) and others (e.g., Chattopadhyay 1999; Tsui and O'Reilly 1989) propose that this will cause negative attitudes toward others and will prevent dissimilar individuals from feelings of commitment to the organization.

Thus, according to the similarity-attraction paradigm and social identity theory, cultural dissimilarity can have negative effects on attitudes and performance. However, there is a lack of empirical evidence addressing the question to what extent minority versus majority members 
would feel committed to their organization. In line with the literature on relational demography, Tsui et al. (1992) found that increased demographic dissimilarity in workgroups was associated with lower levels of organizational commitment. However, larger negative effects were found for majority members than for cultural minorities. Thus, contrary to what is commonly assumed in much race and gender research, it seems that majority members might suffer more from this increased dissimilarity than the minority members (c.f. Tsui et al. 1992). Other research on majority-minority influence in a gender-related context showed the same pattern; men in male-dominated occupations reacted very strongly to the entering of women, which they perceived as a threat to their higher prestige identity (e.g., Hewstone et al. 2001). These studies illustrate that the effects of increased demographic dissimilarity are not necessarily mostly felt by the minorities, as is often assumed (c.f. Tsui et al. 1992), but in fact that the effects seem to be more detrimental for majority members.

These and other studies (Hewstone et al. 2001; Overbeck et al. 2004) emphasize the importance of considering social identity and the relative status of cultural groups. The membership of a minority group is often associated with low status (Hewstone et al. 2001). Being viewed as dissimilar and being a member of a low status group in society, cultural minorities have relatively more difficulty in finding jobs, experience relatively more discrimination than majority members (Oskamp and Schultz 1998), which can lower their career chances in organizations (Cox 1993). In the Netherlands, which is the setting of our study, about a quarter of the employers prefer not to hire ethnic minorities as employees (Kruisbergen and Veld 2002). Indeed, test cases of job candidates those were similar in all respects, except for their ethnicity, revealed discrimination against ethnic minorities by employers in the Netherlands (Bovenkerk et al. 1995). So cultural minorities have to overcome more barriers to become an accepted member of the organization. This low status identity is likely to be unsatisfactory for its members (Overbeck et al. 2004; Ellemers 1991), since research has shown that individuals have a desire to belong to a high status group (c.f. Rijsman 1983). Based on the basic assumptions of social identity theory (Tajfel and Turner 1979; Turner 1982) it can be proposed that if a low status group cannot make a positive contribution to the social identity of its members, these members will try leave this low status group (i.e., individual mobility, Tajfel and Turner 1979) or start to identify with another group with more positively valued characteristics (Overbeck et al. 2004).

Social identity research shows that individuals can identify with two different groups at the same time (Lipponen et al. 2003; Gaertner et al. 1999). Employees in an organization can for instance identify with their workgroup, but also with the organization as a whole, which is seen as a higher level, 'superordinate identity' (Brewer 2000; Lipponen et al. 2003). Since the workgroup identity is part of the organizational identity, this identity is nested within the superordinate organizational identity. Minority members in an organization have a similar situation, in which they can identify with their own cultural group, but also with the organization as a whole. Research shows (Hornsey and Hogg 2002) that when individuals consider their subgroup identity as low status, they are more likely to identify with a superordinate identity. Therefore, we expect that when the identification of cultural minorities with their own low status cultural group is unsatisfactory, they will more strongly start to identify with the organization, as the high status superordinate identity that provides them with a positive social self. This will strongly increase their feelings of commitment to the organization.

In sum, drawing on social identity theory, we expect that minority members have to put more effort in finding a job and becoming a respected member of the organization, because they are member of a low status group. To improve their low status membership, they will be highly motivated to identify with the organization and feel committed to this organization. Majority members, in turn, can experience the presence of minority members as a threat to their own superior identity (Tsui et al. 1992; Hewstone et al. 2001), which can tone down their feelings of commitment to the organization. Therefore, we expect that minority members in the organization will feel relatively more committed to the organization than majority members. This leads us to propose that:

Hypothesis 1 Cultural minority group members will feel more committed to the organization than majority members.

\section{Cultural Minorities and Majorities: Different Socializations}

We now draw onto socialization and acculturation theories to explain different commitment bases of cultural minority versus majority members to the organization. Socialization and acculturation research examine tactics used by organizations, as well as organizational members, to integrate members into the organization (c.f. Lopez and McMillanCapehart 2003). When newcomers are socialized into an organization, they learn the organization's goals, norms, and preferred ways of doing things and come to understand what values and expected behaviors are important to be able to participate as an accepted member (Louis 1980; Jones 1986; Van Maanen and Schein 1979). Research has shown that this socialization process is an ongoing process, which 
is not limited to the first few months or first year of membership, but continues long into the average member's tenure (Kramer and Noland 1999; Waldeck et al. 2004). Acculturation research, in turn, explores how individuals accommodate to new cultures (Berry 1992), and thereby explains what strategy individuals can choose to adapt to an organization with a specific culture (Lopez and McMillanCapehart 2003). In the next sections we will discuss these two different theoretical frameworks, to explain the different sorts of commitment of cultural minority versus majority members, depending on their different socializations in the organization.

Past research on socialization has approached socialization from the organizations' point of view (Allen 2006; Allen and Meyer 1990b; Ashforth and Saks 1996; Myers and McPhee 2006), and often neglected to consider the organizational member's perspective as a participant in this process (c.f. Lopez and McMillan-Capehart 2003). Organizations engage in activities or tactics to learn individuals identifying and adapting to their new role as an organizational member (Chao et al. 1994), and socialization research has focused on this process of adjustment. However, it is important to also consider how a member of the organization member experiences this process, since the socialization process is likely to be even more stressful for members who are different from the majority group in the organization (Lopez and McMillan-Capehart 2003). For instance, research has shown that members who are a minority in terms of culture, gender, or ethnicity, are provided with less information about the politics of the organization and the organization's operations (Ferris et al. 1996), have more difficulty to adapt and attain organizational norms and values created by the majority (Hood and Koberg 1994), are less likely to be tolerated when they express criticism (Hornsey et al. 2002) and have fewer and less-established networks within the organization (Ibarra 1995), than majority members. Therefore, minority members need to put relatively more effort in the process of becoming an accepted and respected member of the organization than majority members need to do.

But what are the consequences for their commitment toward the organization? Research shows that successful socialization results in higher commitment levels in general (Allen and Meyer 1990b; Chao et al. 1994; Cooper-Thomas and Anderson 2002, 2005). However, literature on organizational commitment shows that members can feel committed to an organization out of different reasons. In this study, we want to distinguish different types of commitment and explain how we think strong socialization practices, manifested by a pressure to conform to organizational norms, activate different types of commitment for minority versus majority members. The two types of commitment we distinguish in this study originate from two separate bases (Allen and Meyer 1990a). Normative commitment originates from the responsibilities and obligations employees feel they have toward the organization and is based on a sense of loyalty toward the organization (Allen and Meyer 1990a; De Gilder et al. 1997). Affective commitment reflects the emotional attachment of the employee to the organization, such that a strongly committed employee identifies with the organization and enjoys the membership of the organization (Allen and Meyer 1990a). Consequently, 'employees with strong affective commitment remain because they want to (...) and those with strong normative commitment because they feel they ought to do so.' (Allen and Meyer 1990a, p. 3). Allen and Meyer (1990a, b) state that commitment types can develop independently from each other. It is possible that an employee who feels a moral obligation to the organization does not feel emotionally attached to the organization (De Gilder et al. 1997).

When socialization processes in the organization are strong, members will experience a pressure to conform to the organizational norms, originally set by the majority. Based on research showing that minority members react differently toward socialization practices than majority members (e.g., Ferris et al. 1996; Hornsey et al. 2002), we expect that cultural minorities and majorities will differ in their level and type of commitment to the organization. As we argued earlier, research has shown that for minority members it is more difficult to adjust to the organizational culture than for majority members (Ferris et al. 1996; Hood and Koberg 1994; Ibarra 1995). When organizational norms are created by a group of majority members and members from the minority group feel a pressure to conform and adjust themselves to the norms of this group, they will feel their social identity is being threatened (Branscombe et al. 1993; Ellemers et al. 2002; Ethier and Deaux 1994), since they are outgroup members adjusting to a majority, having little space to live up to their own norms. Consequently, they will feel less emotionally attached to this group and identify less with the group than majority group members. Therefore, we expect that when cultural minorities experience a pressure to conform, they will feel lower levels of affective commitment to the organization than majority members.

This leads us to propose the following:

Hypothesis 2a Pressure to conform moderates the effects of cultural minority membership on affective commitment, such that minority members will perceive relatively lower levels of affective commitment than majority members, when they experience a pressure to conform.

However, as research has shown, strong socialization practices often do result in a certain attachment toward the organization (e.g., Allen and Meyer 1990b; Chao et al. 
1994). We will now draw on acculturation theories to explore how the individual's strategy of adapting oneself to the organization can influence the individual's attachment base toward the organization. Specifically, we will argue how a perceived pressure to conform to organizational norms can positively influence the normative commitment of minority versus majority members.

Acculturation involves a process of cultural change and adaptation between cultural groups, especially when a group is being merged into a larger, more dominant group (Berry 1992). Berry (1992, 1997) has distinguished four acculturation strategies: assimilation, marginalization, separation, and integration. When organizational members change their behavior to match that of the majority group, they have chosen to adopt an assimilation strategy. When organizational members choose not to participate in the organization's majority culture, neither in their own background identity, they adopt a marginalization strategy. Members who are strongly identifying and embracing their own culture practice separation. And organizational members who try to balance the two cultures they are living in, by embracing the majority culture and at the same time maintaining the background identity adopt an integration strategy.

When individuals conform to norms from a dominant group, adopting the values, norms, and beliefs of this dominant group, while suppressing the own cultural identity, they adopt an assimilation strategy (Berry and Sam 1997). In an organization with strong socialization practices, cultural minorities will experience a strong pressure from the organization to conform to the norms of the organization. In this situation, cultural minority members will be more likely to adopt an assimilation strategy. However, acculturation research shows that adopting this strategy can have more detrimental effects on various indicators of mental health than adopting for instance the integration strategy (Berry 1997; Berry and Kim 1988). Cultural minorities who feel that they only can become an accepted member of the organization when they have to assimilate to the norms and values of the majority, may feel they have to suppress their 'background identity' (Lopez and McMillan-Capehart 2003), consisting of personal values, attitudes, behaviors, or beliefs derived from the individuals' cultural background. Denying this cultural background and conforming to the majority group can have negative effects on problem solving and creativity, since this cultural background of individuals forms an important part of the self and affects behaviors and feelings from early childhood on (c.f. Van der Zee et al. 2004). Therefore, we expect that when cultural minorities feel a pressure from the organization to assimilate to the norms of the majority group in the organization, they will commit to the organization because they feel obligated to do so. They do not commit to the organization because they identify themselves with the organization, but out of a sense of loyalty. They will do this more strongly than the majority members in the organization, who commit out of reasons of identification with the organization rather than out of feelings of obligation. This leads us to propose that cultural minority members who feel a pressure to conform will feel more normatively committed than majority members.

Hypothesis 2b Pressure to conform moderates the effects of cultural minority membership on normative commitment, such that minority members will perceive relatively higher levels of normative commitment than majority members, when they experience a pressure to conform.

\section{Effective Leadership}

What can leaders do to facilitate higher employee commitment? We propose that leaders can play an important role in stimulating the commitment of cultural minorities in organizations. Leaders can support cultural minorities by showing confidence in their capacities, thereby stimulating their perceived self efficacy. In addition, leaders who show respect for cultural minorities make them feel that they are being accepted by the organization. Consequently, perceived inequity and unfairness promoted by a less effective leader can decrease the confidence of employees in the organization, which can have a negative effect on the effectiveness of the organization and the commitment of members (Van Breukelen 2004).

However, leaders are not always consistent in their behaviors to different employees they supervise. LeaderMember-Exchange (LMX) theory states that leaders develop different relationships with their subordinates, thereby displaying different behaviors to different members (Yukl 1998) or even discriminate between them (Dansereau 1995). This often leads to the emergence of a favorite ingroup of employees that are highly respected, having a close relationship with their leader and an outgroup of employees who do not (Van Breukelen 2004; Yukl 1998). Research shows that employees who are similar in demographic characteristics have a better relationship with their leader than employees who are not similar (Ashkanasy and O'Connor 1997; Tsui and O'Reilly 1989; Tsui et al. 1995). Therefore, dissimilar individuals in an organization in which majority members represent the management, will have a lower chance of building a good relationship with their supervisor and this may consequently lower their commitment to the organization. Thus, for maintaining the commitment of cultural minorities in organizations it is important that leaders prevent that their cultural minority members become part of this less favorite 
outgroup by treating these members as equal to members of the majority group. As we argued earlier, we expect cultural minorities to be highly motivated to become valued members of the organization and to be accepted as organizational members. Therefore, they will be more sensitive to influence from the organization that indicates to what extent they are being accepted and valued. Leaders in the organization can make cultural minorities feel respected and valued (or not) and provide them with information about how successful they are in acting and performing as an organizational member. Therefore, we expect leadership to have a different impact on minority members versus majority members. We propose that in general, leaders will have a stronger impact on cultural minority members than on majority members and expect a stronger relationship between effective leadership and commitment for cultural minorities than for majority members. We will develop specific hypotheses below, for different leadership styles and how they influence the different sorts of commitment of minority versus majority members.

Similar to the moderating effect of pressure to conform, we expect different types of leadership to be associated with different types of commitment. Past research on leadership defined two broad categories of leadership behaviors, which were labeled 'consideration' and 'initiating structure' (Chemers 1984; Yukl 1998). Consideration is the degree to which leaders display supportive behaviors, i.e., they act in a friendly manner, are concerned with their subordinates and their welfare, consult subordinates when important decisions have to be made, find time to listen to subordinates' problems, and treat subordinates equally (Yukl 1998). Initiating structure is the degree to which leaders structure their own roles and the roles of their subordinates to attain formal goals. This includes criticizing poor work, emphasizing the importance of meeting deadlines, and monitoring the degree to which subordinates follow rules and procedures (Yukl 1998). These categories of leadership correspond to the distinction between taskand people-oriented leadership that was first introduced by Bales (1958). Leadership behaviors that are associated with 'consideration,' such as people-oriented leadership, stress the acceptance of individuals as organizational members and their equality to other members. In a meta-analysis, Judge et al. (2004) showed that consideration is related to leader and job satisfaction, and employee motivation. We expect that leader consideration behaviors will affect employees' feelings of acceptance as an organizational member and therefore their feelings of belonging to the organization. Consequently, we expect that this will increase the affective commitment of employees, since affective commitment is highly associated with feelings of identification with and belonging to the organization (Allen and Meyer 1990a).
Another leadership style that can highly influence the affective commitment of employees is charismatic leadership. Charismatic leaders can have an extraordinary impact on subordinates by articulating ideological goals that are related to the mission of the organization (House 1977). They often provide an appealing future vision to subordinates, which can give more meaning to their work and can make them feel inspired and enthusiastic. A meta-analysis by Judge and Piccolo (2004) on the predictive value of transformational leadership (of which charisma is conceptualized as a subdimension) and transactional leadership shows that charismatic leadership is related to follower job satisfaction, leader satisfaction, and employee motivation, all of which can contribute to employee commitment. Charismatic leaders stimulate the emotional involvement of followers with the mission of the organization and thereby make them more committed to the organization. Since charismatic leadership impresses followers and appeals to feelings of identification with the leader, we expect that charismatic leadership has a positive effect on the affective commitment of especially minority members. Therefore, we hypothesize that:

Hypothesis 3a People-oriented leadership and charismatic leadership moderate the effects of cultural minority/ majority membership on affective commitment, such that people-oriented leadership and charismatic leadership increase affective commitment more for cultural minorities than for majority members.

In contrast, leadership behaviors that are more focused on initiating structure stimulate employees to perform better, to follow the rules and procedures that are stated by the organization and thereby emphasize the obligations employees have to the organization. From the meta-analysis by Judge et al. (2004), we see that initiating structure more strongly relates to performance measures and less strong (although still significant) to leader and job satisfaction and employee motivation than consideration. Initiating structure is aimed to provide role clarity and explicit behavioral norms for employees. As cultural minority members have more difficulty socializing in the organization than majority members (Ferris et al. 1996; Hood and Koberg 1994), they have more to gain by a leadership style that more explicitly clarifies prescribed behaviors and roles as to be able to participate as an accepted member (Louis 1980; Jones 1986; Van Maanen and Schein 1979). As role clarity may increase organizational commitment, we argue that a leadership style characterized by initiating structure is thus especially helpful for cultural minorities in comparison to majorities. Because this type of leadership behavior provides the employee with clear guidance and role clarity we expect task-oriented leadership to be more associated with normative commitment, since normative 
commitment represents employees' loyalty and responsibility to the organization (Allen and Meyer 1990a). This leads us to propose the following:

Hypothesis 3b Task-oriented leadership moderates the effects of cultural minority-majority membership on normative commitment, such that task-oriented leadership increases normative commitment more for cultural minorities than for majority members.

\section{Method}

Participants and Procedure

We conducted a field study in a Dutch multinational in the field of electronics. In total, we distributed 280 questionnaires; 109 questionnaires were returned, of which we were able to use 107 ( 2 were discarded due to missing data). This response rate of $39 \%$ is considered as a good response rate in field research (Baker 1994). The anonymity of respondents was guaranteed. The educational level of half of the participants $(50.5 \%)$ was high school level and the other half $(49.5 \%)$ had technical/vocational training. The average tenure of employees was 5 years, mainly consisting of men (94.4\%) between 21 and 54 years of age (mean $=33.6)$. Almost $79 \%(78.5 \%)$ of the participants were cultural-majority members (Dutch nationality), 20.6\% were cultural minorities ( $0.9 \%$ was missing). This percentage of cultural minorities corresponds with the national percentage of cultural minorities that is employed in organizations in the Netherlands (CBS 2007) and is thereby a representative proportion relative to the proportion of majority members in organizations. The cultural minorities in our sample came from the following regions: Turkey (6.6\%), Morocco (3.8\%), Africa (non-Maghreb) (3.7\%), Western-Europe (2.8\%), Antilles (1.9\%), Balkan (1.9\%).

\section{Measurements}

We used existing scales to measure the concepts in our study and for pressure to conform we created our own measurement. We asked participants to answer all items on a 1-5 Likert scale.

\section{Commitment}

For the measurement of affective and normative commitment, we used the Dutch translation and edition (De Gilder et al. 1997) of the original instrument of Allen and Meyer (1990), as all participants were Dutch speaking. The scales consisted of 5 items for affective and 5 items for normative commitment. Sample items for affective commitment were: 'I enjoy discussion organization X with other people' and ' $I$ feel a strong sense of belonging to organization X'. For normative commitment we used: 'I believe that a person should be loyal to his or her organization' and 'I find it important to be loyal to organization X'. The internal consistency of the two types of commitment was good (affective commitment $\alpha=.72$, normative commitment $\alpha=.85$ ).

\section{Leadership}

We measured leadership using the Dutch translation and edition (Van Engen 2001) of the Supervisory Behavior Description Questionnaire (SBDQ) of Fleishman (1953) for task-oriented leadership (5 items) and people-oriented leadership (5 items). For charismatic leadership (5 items), we used the Dutch translation and revision (Van Engen 2001; Den Hartog et al. 1994) of the Multifactor Leadership Questionnaire (MLQ, Bass and Avolio 1989). Sample items for task-oriented leadership were: 'My supervisor urges me to make more of an effort' and 'My supervisor tempts me to perform better'. For people-oriented leadership we used: 'My supervisor supports me in my work' and 'My supervisor compliments me when I performed my work well'. Sample items for charismatic leadership were: 'My supervisor is a role model for me' and 'My supervisor knows solutions for every single problem'. Our factor analysis showed three underlying factors, confirming the three leadership styles. The Cronbach's alpha of the leadership styles were: people-oriented leadership $\alpha=.89$, task-oriented leadership $\alpha=.63$, charismatic leadership $\alpha=.82$.

\section{Pressure to conform}

Since instruments measuring employees' perceived pressure to conform to the organization norms were lacking, we developed our own instrument. Based on Berry's (1997) thoughts on acculturation, we measured the organizations' pressure to conform, using 5 items, asking to what extent participants felt they should adapt to organizational norms to be regarded as a member of the organization. Sample items were: 'I really feel I have to adapt myself to the rules of organization X', 'Only when I assimilate to organization $\mathrm{X}$, will I belong to it' or 'When I want to belong to organization X, I cannot be myself'. The Cronbach's alpha of this scale was .70 .

We measured the cultural background of participants by asking their nationality at birth. We found no differences across the minority groups on our dependent variables. Therefore, following past research (e.g., Ibarra 1995; Tsui et al. 1992), we created a dichotomous variable majorityminority group membership to match our conceptualization. 


\section{Results}

Table 1 includes the means, standard deviations, and correlations among the variables in our study for minority members versus majority members separately. In line with what we proposed in hypothesis 1 , the correlation table shows that the means for both affective and normative commitment are higher for minority members (affective commitment $M=3.55$ and normative commitment $M=$ 3.27 ) than for majority members (affective commitment $M=3.17$, normative commitment $M=2.53$ ). We find a marginal positive correlation between pressure to conform and normative commitment, but we only find this for minority members $(r=.39, p=.08)$. Also, we find significant positive correlations between people- $(r=.51$, $p<.05)$ and task-oriented leadership $(r=.81, p<.01)$ and normative commitment, specifically for minority members. For majority members, we only find a marginal positive correlation between charismatic leadership and normative commitment $(r=.21, p=.07)$. This analysis revealed that effect sizes for the minority subsample would need to be more than .50 to be identified as statistically significant, which means that even moderate effects would not be detected with an alpha level of .05. Therefore, the alpha level was set at .10, meaning that the probability of a Type-I error was increased but made the detection of effects more likely (Cohen 1988). This is an accepted procedure in diversity research (e.g., Mason 2006). Below, we will now discuss our hypothesis testing.

In hypothesis 1 , we proposed that cultural minorities will feel more committed to the organization than majority members. To test this hypothesis, we compared the means of the two groups in an ANOVA for both affective and normative commitment. The ANOVA showed significant differences for affective commitment $(F(1,105)=$ 9.57, $p<.01)$, as well as for normative commitment
$(F(1,105)=24.40, p<.001)$. Cultural minorities felt more affectively $(M=3.55$ vs. $M=3.17$ for majority members) and more normatively committed ( $M=3.27$ vs. $M=2.53$ for majority members).

Hypothesis 2 a proposed that pressure to conform moderates the effects of cultural minority membership on affective commitment, such that pressure to conform decreases the affective commitment more for minorities than for majorities. To test this hypothesis, we first regressed pressure to conform and cultural identity (minority, majority) on affective commitment and added the interaction term (cultural identity $\times$ pressure to conform) in a next step. As can be seen in Table 2, the results of our regression analysis did not support this hypothesis. Hypothesis $2 b$ proposed that pressure to conform moderates the effects of cultural minority membership on normative commitment, such that pressure to conform increases the normative commitment more for members of the cultural minority group than for members of the cultural majority. The regression analysis showed a marginal interaction-effect in the second step $(\beta=.83, t=1.75, p=.08$ ), thereby showing some support for the hypothesis. The interaction contributed to a marginal increment in the regression model $\left(R^{2}=.22, F\right.$ change $\left.=3.06, p=.08\right)$. Thus, cultural minorities felt more normatively committed, in particular when they perceived an organizational pressure to conform.

In hypothesis $3 \mathrm{a}$, we proposed that people-oriented leadership and charismatic leadership will moderate the effects of cultural minority/majority membership on affective commitment, such that people-oriented leadership and charismatic leadership will increase affective commitment more for cultural minorities than for majority members. To test this hypothesis, we first regressed people-oriented leadership and charismatic leadership and cultural identity (minority, majority) on affective commitment and added the interaction term (cultural identity $\times$ people-oriented

Table 1 Means, standard deviations and correlations among variables for minority ${ }^{\mathrm{a}}$ members and majority ${ }^{\mathrm{b}}$ members

\begin{tabular}{|c|c|c|c|c|c|c|c|c|}
\hline & $M$ & SD & 1 & 2 & 3 & 4 & 5 & 6 \\
\hline$M$ & & & 2.55 & 3.68 & 3.21 & 3.30 & 3.17 & 2.53 \\
\hline SD & & & .57 & .49 & .49 & .60 & .50 & .61 \\
\hline Pressure to conform & 2.85 & .55 & - & $-.48 * *$ & .05 & $-.27^{*}$ & $-.33 * *$ & .00 \\
\hline People-oriented leadership & 3.77 & .41 & -.09 & - & $.26^{*}$ & $.78 * *$ & $.43 * *$ & .07 \\
\hline Task-oriented leadership & 3.29 & .58 & .29 & .37 & - & $.34 * *$ & $.25^{*}$ & .07 \\
\hline Charismatic leadership & 3.47 & .65 & -.05 & $.61 * *$ & .30 & - & $.41 * *$ & $.21^{\dagger}$ \\
\hline Affective commitment & 3.55 & .56 & .02 & $.52 *$ & $.49 *$ & $.61 * *$ & - & $.55^{* *}$ \\
\hline Normative commitment & 3.27 & .68 & $.39^{\dagger}$ & $.51 *$ & $.81 * *$ & .27 & $.56 * *$ & - \\
\hline
\end{tabular}

Notes: $N=104-106$

${ }^{\dagger} p<.10 ; * p<.05 ; * * p<.01 ; * * * p<.001$

${ }^{a}$ Means, standard deviations, and correlations are displayed at the lower left corner of the table

b Means, standard deviations, and correlations are displayed at the upper right corner of the table 
Table 2 Hierarchical regression analysis of pressure to conform, majority-minority on commitment

\begin{tabular}{|c|c|c|c|c|c|}
\hline \multirow[t]{2}{*}{ Step } & & \multicolumn{2}{|c|}{ Affective commitment } & \multicolumn{2}{|c|}{ Normative commitment } \\
\hline & & $\beta$ & $\beta$ & $\beta$ & $\beta$ \\
\hline \multirow[t]{2}{*}{1} & Pressure to conform & $-.25^{* *}$ & $-.31 * *$ & .07 & -.00 \\
\hline & Majority-minority ${ }^{\mathrm{a}}$ & $.35 * * *$ & -.32 & $.42 * * *$ & -.37 \\
\hline \multirow[t]{4}{*}{2} & PTC $\times$ Majority-minority ${ }^{\mathrm{a}}$ & & .69 & & $.83^{\dagger}$ \\
\hline & $F$ & $8.51 * * *$ & $6.39 * * *$ & $12.49 * * *$ & $9.51 * * *$ \\
\hline & $R^{2}$ & .14 & .16 & .20 & .22 \\
\hline & $\Delta R$ & $.14 * * *$ & .02 & $.20 * * *$ & $.02^{\dagger}$ \\
\hline
\end{tabular}

PTC pressure to conform

${ }^{\dagger} p<.10 ; * p<.05 ; * * p<.01 ; * * * p<.001$

${ }^{\mathrm{a}} 0=$ majority, $1=$ minority

Table 3 Hierarchical regression analysis of effective leadership, majority-minority on commitment

\begin{tabular}{|c|c|c|c|c|c|}
\hline \multirow[t]{2}{*}{ Step } & & \multicolumn{2}{|c|}{ Affective commitment } & \multicolumn{2}{|c|}{ Normative commitment } \\
\hline & & $\beta$ & $\beta$ & $\beta$ & $\beta$ \\
\hline \multirow[t]{4}{*}{1} & PO leadership & .20 & $.26^{\dagger}$ & -.08 & $-.24^{\dagger}$ \\
\hline & TO leadership & $.17^{\dagger}$ & .13 & $.36^{* * *}$ & $.24^{*}$ \\
\hline & $\mathrm{CH}$ leadership & $.24^{\dagger}$ & .14 & .15 & $.32 *$ \\
\hline & Majority-minority ${ }^{a}$ & $.25^{* *}$ & -.51 & $.42 * * *$ & $-1.48^{*}$ \\
\hline \multirow[t]{6}{*}{2} & $\mathrm{PO} \times$ majority-minority & & -.30 & & $1.92 *$ \\
\hline & $\mathrm{TO} \times$ majority-minority & & .42 & & $1.06^{*}$ \\
\hline & $\mathrm{CH} \times$ majority-minority & & .66 & & $-1.06^{\dagger}$ \\
\hline & $F$ & $11.81 * * *$ & $7.06 * * *$ & $13.49 * * *$ & $9.73 * * *$ \\
\hline & $R^{2}$ & .33 & .33 & .36 & .42 \\
\hline & $R^{2}$ change & $.33 * * *$ & .02 & $.36 * * *$ & $.06 *$ \\
\hline
\end{tabular}

$P O$ people oriented, $\mathrm{TO}$ task oriented, $\mathrm{CH}$ charismatic

${ }^{\dagger} p<.10 ; * p<.05 ; * * p<.01 ; * * * p<.001$

${ }^{\mathrm{a}} 0=$ majority, $1=$ minority

leadership and cultural identity $\times$ charismatic leadership) in the second step. The analyses did not support this hypothesis (see Table 3).

Hypothesis $3 \mathrm{~b}$, proposing that task-oriented leadership moderates the effects of cultural minority-majority membership on normative commitment, such that task-oriented leadership increases normative commitment more for cultural minorities than for majority members, was supported. Hierarchical regression analyses (see Table 3) showed that task-oriented leadership indeed moderated the relationship between cultural minority-majority membership and normative commitment $(\beta=1.06, t=2.05, p<.05)$.

In contrast to what we expected, however, people-oriented leadership and charismatic leadership also (marginally) moderated the relationship between cultural minority/majority membership on normative commitment, instead of on affective commitment, as we proposed (see Table 3). At step 2, both interactions between taskand people-oriented leadership with majority-minority membership on normative commitment became significant and charismatic leadership had a marginal effect, contributing to a significant $R^{2}$ increment $\left(R^{2}\right.$ change $=.06$, $F$ change $=3.40, p<.05)$. Thus, cultural minorities felt more normatively committed to the organization, in particular when leaders showed task- and people-oriented leadership styles.

\section{Discussion}

In this field study, we examined the effects of being a cultural minority or majority group member on the organizational commitment of these members in a multicultural organization. We argued and found that cultural minorities feel more committed than majority members, thereby challenging the existent theoretical view that cultural minorities feel less committed to the organization. In doing this, we made an empirical contribution to the few studies 
that actually tested this proposition in the field (c.f. Tsui et al. 1992; Riordan and Shore 1997). However, as the sample size for minorities in this study was relatively small, the generalization of results is limited. Therefore, future research should replicate this study with a larger sample of minorities (as well as majorities) in the population.

In addition, we proposed two moderator variables: pressure to conform and effective leadership. We found (marginal) support for the hypothesis that pressure to conform moderates the relationship between majority-minority membership and normative commitment, such that pressure to conform increases the normative commitment more for members of the cultural minority group than for members of the cultural majority. The finding that pressure to conform is more associated with normative commitment than with affective commitment is not surprising, since both concepts are linked to obligations and norms that prescribe how things ought to be done. Affective commitment, in turn, represents the emotional attachment of individuals to the organization, which is a different concept. We also found the expected effect of task-oriented leadership on normative commitment, such that task-oriented leadership makes cultural minorities more aware of their obligations and responsibility to the organization, and increases their feeling of loyalty to the organization.

While we did not find our hypothesized effect of peopleoriented and charismatic leaderships on affective commitment, we did find that task-oriented leadership increased normative commitment more for minorities than for majorities. In this study, it appears that the normative commitment of cultural minorities to the organization is more salient and more easily influenced by contextual factors than affective commitment. Since cultural minorities often have more difficulties to integrate and socialize in organizations (Hood and Koberg 1994; Hornsey et al. 2002; Ibarra 1995), it might be that cultural minorities are more focused on how they ought to behave as accepted organizational members, being more aware of their obligations and responsibilities toward the organization, which makes them feel more normatively committed in general. Therefore, future research should focus more on the reasons behind the commitment of minority and majority members and examine how contextual factors can influence this, as well as more directly testing the social identity mechanisms challenged by these findings. The routes leading to organizational commitment might be different for cultural minorities than for majority members. Majority members might commit out of social identity reasons, while minority members might commit out of a superordinate identity. Therefore, future research should actually measure identification with different social groups in the organization (superordinate organizational identity, or common identity, and cultural identities) to test whether the commitment of minority versus majority members have different underlying processes.

Despite the fact that we found strong support for our main hypothesis those cultural minorities would feel more affectively and normatively committed than majority members, future research should replicate these finding with a larger sample size. It might be that due to the low sample size and thus the lack of statistical power, we did not find some of the proposed relationship, especially regarding the moderator hypotheses.

Future research should also examine different proportions of minority subsamples relative to the majority group to see if the effects will then change (Kanter 1977; Williams and O'Reilly 1998; Tsui et al. 1992). The race relations literature suggests that it is more likely that majority members will tolerate minority members when they represent only a small proportion of the group (Pettigrew 1980). However, the study of Tsui et al. (1992) shows that the presence of even a small proportion of minority members decreased the commitment of majority members, while the minority members were not negatively affected in their commitment. It seems that different proportions of minority and majority members prime salient categories (Williams and O'Reilly 1998), which has different effects on minority and majority members. Therefore, future research should examine the effect of different proportion of minorities in a majority group.

Another future direction to gain better insight into the influence of socialization processes in organizations on the commitment of majority and minority members, is to more specifically measure the mechanisms underlying acculturation research (c.f. Berry et al. 1986; Berry 1997), by for instance examining the process of cultural change and adaption between members of the majority and minority group when they interact (Berry 1997; Rodriquez et al. 2002). The extent to which minority and majority members are oriented toward the other cultural group and identify with their own ethnic identity (Molina et al. 2004) can influence their commitment to the organization (Cox 1993). An examination of these processes in a multi-organization study, comparing the different socialization (c.f. Caldwell et al. 1990) and acculturation practices in organizations, would also allow replication of our findings across multiple organizations.

Our findings have important implications for both research and practice. First, we challenge the existing theoretical view based on similarity attraction theory and relational demography theory, that cultural minorities would feel less committed to the organization. We argued that minority members are highly motivated to act in line with the organizations' goals, since they have to overcome many barriers to find a job (Bovenkerk et al. 1995) and are 
motivated to become a valued member of the high-status organization, which provides them a positive social identity. Majority members, in turn, feel less committed due to the increased dissimilarity in the organization, which threatens their privileged position. The findings supported our hypothesis that minority members will feel more committed to the organization than majority members, thereby indicating that organizational leaders (and researchers) should focus not only on increasing and maintaining the commitment of minority members, but also should pay attention to members of the cultural majority in socialization and integration processes. Most past research ignored the reaction of the majority to the presence of minority members (Tsui et al. 1992) and therefore, future research should pay more attention to majority reactions to dissimilarity in organizations.

Secondly, we found that pressure to conform and effective leadership increased the normative commitment of organizational members, but more for minorities than for majorities. As we mentioned, the normative commitment of minority members appears to be more salient and more easily influenced by organizational factors than affective commitment. Practitioners may have to ask themselves what type(s) of commitment they need to meet the organizational goals. It can be argued that affective commitment is more associated with an internal motivation to reach organizational goals, while normative commitment is based on a more external motivation to meet the expectancies and obligations the organization poses. It can be possible that, depending on the type of organization or job content, some organizations have a specific need for internally motivated employees, while others are effective with more externally motivated employees. However, little research has been done on the consequences of different types of commitment and the relationship with external and internal motivation bases (Mathieu and Zajac 1990). Therefore, future research should focus more on the consequences of different types of commitment for the organization and how these different types can be enhanced for minority and majority members.

In this study, we already found some contextual factors that influenced commitment. For example, we found that effective leadership can increase the commitment of majorities but does so more for minority members than for majority members. Thus, effective leadership can be an important variable in the enhancement of the commitment of both minority and majority members. More research should be done on how leaders can enhance the commitment of majority members in a multicultural organization. In addition, we found that pressure to conform to organizational norms enhances the normative commitment of minority members, which can be seen as an important variable in the socialization process of organizations.
In conclusion, for the enhancement of the commitment of both majority and minority members, researchers, and practitioners should focus on contextual factors that influence commitment and they should consider the consequences of specific types of commitment. When disentangling the factors that influence the commitment of majority and minority members, researchers, and practitioners will be able to better minimize the negative effects of increased dissimilarity on majority members and stimulate the commitment of members of both the groups.

Open Access This article is distributed under the terms of the Creative Commons Attribution Noncommercial License which permits any noncommercial use, distribution, and reproduction in any medium, provided the original author(s) and source are credited.

\section{References}

Allen, D. G. (2006). De organizational socialization tactics influence newcomer embeddedness and turnover? Journal of Management, $32,237-256$.

Allen, N. J., \& Meyer, J. P. (1990a). The measurement and antecedents of affective, continuance and normative commitment to the organization. Journal of Occupational and Organizational Psychology, 63, 1-18.

Allen, N., \& Meyer, J. (1990b). Organizational socialization tactics: A longitudinal analysis of links to newcomers' commitment and role orientation. Academy of Management Journal, 33(4), $847-858$.

Arends-Tóth, J., \& Van de Vijver, F. J. R. (2001). Het belang van acculturatie voor organisaties. Gedrag en Organisatie, 14, 37-55.

Ashforth, B. E., \& Saks, A. M. (1996). Socialization tactics: Longitudinal effects on newcomer adjustment. Academy of Management Journal, 39(1), 149-179.

Ashkanasy, N. M., \& O'Connor, C. (1997). Value congruence in leader-member exchange. The Journal of Social Psychology, 137, 647-662.

Baker, T. L. (1994). Doing social research (2nd ed.). Singapore: McGraw-Hill.

Bales, R. F. (1958). Task roles and social roles in problem solving groups. In E. E. Macoby, T. M. Newcomb, \& E. C. Hartley (Eds.), Social psychology (3rd ed., pp. 437-447).

Bass, B. M., \& Avolio, B. J. (1989). Manual for the multifactor leadership questionnaire. Palo Alto, CA: Consulting Psychologists Press.

Benschop, Y. (2001). Pride, prejudice and performance: Relations between HRM, diversity and performance. International Journal of Human Resource Management, 12, 1166-1181.

Berry, J. W. (1992). Acculturation and adaptation in an new society. International Migration, 30, 69-85.

Berry, J. W. (1997). Immigration, acculturation and adaption. Applied Psychology: An International Review, 46, 5-34.

Berry, J. W., \& Kim, U. (1988). Acculturation and mental health. In P. Dasen, J. W. Berry, \& N. Sartorius (Eds.), Health and crosscultural psychology (pp. 207-236). Newbury Park: Sage.

Berry, J. W., \& Sam, D. L. (1997). Acculturation and adaptation. In J. W. Berry \& C. Kagitcibasi (Eds.), Handbook of cross-cultural psychology: social behavior and applications (Vol. 3, pp. 291326). Boston: Allyn and Bacon.

Berry, J. W., Trimble, J. E., \& Olmedo, E. L. (1986). Assessment of acculturation. In W. J. Lonner \& J. W. Berry (Eds.), Field 
methods in cross-cultural research (pp. 291-324). Thousand Oaks, CA: Sage.

Berscheid, E., \& Walster, H. (1987). Interpersonal attraction. Reading, MA: Addison-Wesley.

Bovenkerk, F., Gras, M. J. I., Ramsoedh, D., Dankoor, M., \& Havelaar, A. (1995). Discrimination against migrant workers and ethnic minorities in access to employment in the Netherlands. International Migration papers 4, International Labor Office.

Branscombe, N. R., Wann, D. L., Noel, J. G., \& Coleman, J. (1993). Ingroup or outgroup extremity: Importance of the threatened identity. Personality and Social Psychology Bulletin, 19, 381-388.

Brewer, M. B. (2000). Superordinate goals versus superordinate identity as bases of intergroup cooperation. In D. Capozza \& R. Brown (Eds.), Social identity processes: Trends in theory and research (pp. 117-132). Thousand Oaks, CA: Sage Publications.

Buchanan, B. (1974). Building organanizational commitment: The socialization of managers in work organizations. Administrative Science Quarterly, 19, 533-546.

Byrne, D. E. (1971). The attraction paradigm. New York: Academic Press.

Caldwell, D. F., Chatman, J. A., \& O'Reilly, C. A. (1990). Building organizational commitment: A multifirm study. Journal of Occupational and Organizational Psychology, 63, 245-261.

Central Bureau for Statistics (CBS). (2007). Labour force according to gender and age. Voorburg/Heerlen.

Chao, G., O'Leary-Kelly, A., Wolf, S., Klein, H., \& Gardner, P. (1994). Organizational socialization: Its content and consequences. Journal of Applied Psychology, 79(5), 730-743.

Chatman, J. A., Polzer, J. T., Barsade, S. G., \& Neale, M. A. (1998). Being different yet feeling similar: The influence of demographic composition and organizational culture on work processes and outcomes. Administrative Science Quarterly, 43, 749-780.

Chattopadhyay, P. (1999). Beyond direct and symmetrical effects: The influence of demographic dissimilarity on organizational citizenship behavior. Academy of Management Journal, 42, 273-287.

Chemers, M. M. (1984). The social, organizational and cultural context of effective leadership. In B. Kellerman (Ed.), Leadership: Multidisciplinary perspectives (pp. 91-112). Englewood Cliffs, NJ: Prentice-Hall.

Chemers, M. M., Oskamp, S., \& Constanzo, M. A. (1995). Diversity and organizations: New perspectives for a changing workplace. Thousand Oaks, CA: Sage Publications.

Cohen, J. (1988). Statistical power analyses for the behavioral sciences (2nd ed.). New York: Academic Press.

Cooper-Thomas, H. D., \& Anderson, N. (2002). Newcomer adjustment: The relationship between organizational socialization tactics, information acquisition and attitudes. Journal of Occupational and Organizational Psychology, 75, 423-437.

Cooper-Thomas, H. D., \& Anderson, N. (2005). Organizational socialization: A field study into socialization success and rate. International Journal of Selection and Assessment, 13, 116-128.

Cox, T. (1993). Cultural diversity in organizations: Theory, research and practice. San Francisco: Berret-Koehler Publishers.

Dansereau, F. (1995). A dyadic approach to leadership: Creating and nurturing this approach under fire. Leadership Quarterly, 6, 479-490.

De Gilder, D., Van den Heuvel, H., \& Ellemers, N. (1997). Het 3-componenten model van commitment. Gedrag en Organisatie, 10(2), 95-106.

Den Hartog, D., Van Muijen, J., \& Koopman, P. (1994). Leiderschap: Een analyse van de MLQ in de Nederlandse situatie. Gedrag en Organisatie, 7, 155-166.

Dougherty, D. (1992). Interpretive barriers to successful product innovation in large firms. Organization Science, 3(2), 179202.
Ellemers, N. (1991). Identity management strategies: The influence of socio-structural variables on strategies of individual mobility and social change. Dissertation, University of Groningen, Groningen.

Ellemers, M., Spears, R., \& Doosje, B. (2002). Self and social identity. Annual Review of Psychology, 53, 161-186.

Ely, R. J., \& Thomas, D. A. (2001). Cultural diversity at work: The effects of diversity perspectives on work group processes and outcomes. Administrative Science Quarterly, 46, 229-273.

Ethier, K. A., \& Deaux, K. (1994). Negotiating social identity in a changing context: Maintaining identification and responding to threat. Journal of Personality and Social Psychology, 67, 243-251.

Ferris, G. R., Frink, D. D., Bhawuk, D. P. S., Zhou, J., \& Gilmore, D. C. (1996). Reactions of diverse groups to politics in the workplace. Journal of Management, 22(1), 23-44.

Fleishman, E. A. (1953). The description of supervisory behavior. Journal of Applied Psychology, 37, 1-6.

Gaertner, S. L., Dovidio, J. F., Nier, J. A., Ward, C. M., \& Banker, B. S. (1999). Across cultural divides: The value of a superordinate identity. In Cultural divides: Understanding and overcoming group conflict (pp. 173-212). New York: Russell Sage Foundation.

Hewstone, M., Martin, R., Hammer-Hewstone, C., Crisp, R., \& Voci, A. (2001). Majority-minority relations in organizations: Challenges and opportunities. In M. A. Hogg \& D. J. Terry (Eds.), Social identity processes in organizational contexts (pp. 67-86). Ann Arbor: Sheridan Books.

Hood, J., \& Koberg, C. (1994). Patterns of differential assimilation and acculturation for women in business organizations. Human Relations, 47(2), 159-182.

Hornsey, M. J., \& Hogg, M. A. (2002). The effects of status on subgroup relations. British Journal of Social Psychology, 41, 203-218.

Hornsey, M. J., Oppes, T., \& Svensson, A. (2002). It's ok if we say it, but you can't. European Journal of Social Psychology, 32(3), 293-307.

House, R. J. (1977). A 1976 theory of charismatic leadership. In J. G. Hunt \& L. L. Larson (Eds.), Leadership: The cutting edge. Carbonadale, IL: Southern Illinois University Press.

Ibarra, H. (1995). Race, opportunity and diversity of social circles in managerial networks. Academy of Management Journal, 38, 673-703.

Jackson, S. E., Joshi, A., \& Erhardt, N. L. (2003). Recent research on teams and organizational diversity: SWOT analysis and implications. Journal of Management, 29(6), 801-830.

Jackson, S. E., Stone, V. K., \& Alvaraz, E. B. (1992). Socialization amidst diversity: The impact of demographics on work team oldtimers and newcomers. Research in organizational behavior, $15,45-109$.

Jehn, K. A., \& Bezrukova, K. (2004). A field study of group diversity, workgroup context, and performance. Journal of Organizational Behavior, 25, 703-729.

Jehn, K., Northcraft, G., \& Neale, M. (1999). Why differences make a difference: A field study of diversity, conflict, and performance in workgroups. Administrative Science Quarterly, 44, 741-763.

Jones, G. R. (1986). Socialization tactics, self-efficacy, and newcomers' adjustments to organizations. Academy of Management Journal, 29(2), 262-279.

Judge, T. A., \& Piccolo, R. F. (2004). Transformational and transactional leadership: A meta-analytic test of their relative validity. Journal of Applied Psychology, 89, 901-910.

Judge, T. A., Piccolo, R. F., \& Ilies, R. (2004). The forgotten ones? The validity of consideration and initiating structure in leadership research. Journal of Applied Psychology, 89, 36-51.

Kanter, R. M. (1977). Some effects of proportions on group life: Skewed sex ratios and responses to token women. American Journal of Sociology, 82, 965-990. 
Kramer, M. W., \& Noland, T. L. (1999). Communication during job promotions: A case of ongoing assimilation. Journal of Applied Communication Research, 27, 225-255.

Kruisbergen, E., \& Veld, T. (2002). Een gekleurd beeld: Over beelden, beoordeling en selectie van jonge allochtone werknemers, [A coloured picture: About images, judgments and selection of young ethnic minority employees]. Assen: Van Gorcum.

Lipponen, J., Helkama, K., \& Juslin, M. (2003). Subgroup identification, superordinate identification and intergroup bias between the subgroups. Group Processes \& Intergroup Relations, 6(3), 239-250.

Lopez, T., \& McMillan-Capehart, A. (2003). How outgroup sales people fit in or fail to fit in: A proposed acculturation effects framework. Journal of Personal Selling \& Sales Management, 12, 297-309.

Louis, M. L. (1980). Surprise and sense-making: What newcomers experience in entering unfamiliar organizational settings. Administrative Science Quarterly, 25, 226-251.

Mannix, E. A., \& Neale, M. A. (2005). What differences make a difference? The promise and reality of diverse teams in organizations. Psychological Science in the Public Interest, 6(2), 31-55.

Mason, C. M. (2006). Exploring the processes underlying withingroup homogeneity. Small Group Research, 37(3), 233-270.

Mathieu, J. E., \& Zajac, D. (1990). A review and meta-analysis of the antecedents, correlates, and consequences of organizational commitment. Psychological Bulletin, 108, 171-194.

Molina, L. E., Wittig, M. A., \& Giang, M. T. (2004). Mutual acculturation and social categorization: A comparison of two perspectives on intergroup bias. Group Processes and Intergroup Relations, 7(3), 239-265.

Myers, K. K., \& McPhee, R. D. (2006). Influences on member assimilation in workgroups in high-reliability organizations: A multilevel analysis. Human Communication Research, 32(4), 440-468.

Oskamp, S., \& Schultz, P. W. (1998). Applied social psychology (2nd ed.). Englewood Cliffs, NJ: Prentice-Hall.

Overbeck, J. R., Jost, J. T., Mosso, C. O., \& Flizik, A. (2004). Resistant versus acquiescent responses to ingroup inferiority as a function of social dominance orientation in the USA and Italy. Group Processes and Intergroup Relations, 7(1), 35-54.

Pelled, L. H., Eisenhardt, K. M., \& Xin, K. R. (1999). Exploring the black box: An analysis of work group diversity, conflict and performance. Administrative Science Quarterly, 44, 1-28.

Pettigrew, T. F. (Ed.). (1980). The sociology of race relations: Reflection and reform. New York: Free Press.

Rijsman, J. (1983). The dynamics of social competition in personal and categorical comparison-situations. In W. Doise \& S. Moscovici (Eds.), Current issues in European social psychology (Vol. 1, pp. 279-312). Cambridge: Cambridge University Press.

Riketta, M., \& Van Dick, R. (2005). Foci of attachment in organizations: A meta-analytic comparison of the strength and correlates of workgroup versus organizational identification and commitment. Journal of Vocational Behavior, 67, 490-510.

Riordan, C. M. (2000). Relational demography within groups, past developments, contradictions, and new directions. Research in Personnel \& Human Resource Management, 19, 131-173.

Riordan, C. M., \& Shore, L. M. (1997). Demographic diversity and employee attitudes: An empirical examination of relational demography within work units. Journal of Applied Psychology, 83(3), 342-358.

Rodriquez, N., Myers, H. F., Mira, C. B., Flores, T., \& GarciaHernandez, L. (2002). Development of the multidimensional acculturative stress inventory for adults of Mexican origin. Psychological Assessment, 14(4), 451-461.

Stewart, G. L. (2006). A meta-analytic review of relationships between team design features and team performance. Journal of Management, 32(1), 29-54.

Tajfel, H. (1978). Social categorization, social identity, and social comparison. In H. Tajfel (Ed.), Differentiation between social groups, studies in the social psychology of intergroup relations (pp. 61-76). London: Academic Press.

Tajfel, H., \& Turner, J. C. (1979). An integrative theory of intergroup conflict. In W. G. Austin \& S. Worchel (Eds.), The social psychology of intergroup relations (pp. 33-48). Monterey, CA: Brooks/Cole.

Tajfel, H., \& Turner, J. C. (1986). The social identity theory of intergroup behavior. In S. Worchel \& W. G. Austin (Eds.), Psychology of intergroup relations (pp. 7-24). Chicago: NelsonHall.

Thomas, D. A., \& Ely, R. (1996). Making differences matter: A new paradigm in managing diversity. Harvard Business Review, 74, $118-128$.

Tsui, A., Egan, T. D., \& O'Reilly, C. A. (1992). Being different: Relational demography and organizational attachment. Administrative Science Quarterly, 37, 549-579.

Tsui, A., \& O'Reilly, C. A. (1989). Beyond simple demographic effects: The importance of relational demography in superior subordinate dyads. Academy of Management Journal, 32(2), $402-423$.

Tsui, A. S., Xin, K. R., \& Egan, T. D. (1995). Relational demography: The missing link in vertical dyad linkage. In S. E. Jackson \& M. N. Ruderman (Eds.), Diversity in work teams (pp. 97-130). Washington, DC: American Psychological Association.

Turner, J. (1982). Towards a cognitive redefinition of the social group. In H. Tajfel (Ed.), Social identity and intergroup relations (pp. 15-40). Cambridge: Cambridge University Press.

Van Breukelen, W. (2004). Flexibilisering en management. In F. Glastra, S. Van der Haar, M. Lens, \& P. Schedler (Eds.), Losse koppelingen: Over flexibilisering van arbeid, organisatie en leefwereld's. Gravenhage: Reed Business Information.

Van der Zee, K., Atsma, N., \& Brodbeck, F. (2004). The influence of social identity and personality on outcomes of cultural diversity in teams. Journal of cross-cultural psychology, 35(3), 283-303.

Van Engen, M. L. (2001). Gender and leadership: A contextual perspective. Dissertation, Tilburg University, Tilburg.

Van Maanen, J., \& Schein, E. H. (1979). Toward a theory of organizational socialization. In B. Staw \& L. L. Cummings (Eds.), Research in organizational behavior (Vol. 1, pp. 209264). Greenwich, CT: JAI Press.

Von Glinow, M. A., Shapiro, D. L., \& Brett, J. M. (2004). Can we talk, and should we? Managing emotional conflict in multicultural teams. Academy of Management Review, 29(4), 578-592.

Waldeck, J., Seibold, D., \& Flanagin, A. (2004). Organizational assimilation and communication technology use. Communication Monographs, 71(2), 161-183.

Webber, S., \& Donahue, L. (2001). Impact of highly and less jobrelated diversity on work group cohesion and performance: A meta-analysis. Journal of Management, 27, 141-162.

Williams, K. Y., \& O'Reilly, C. A. (1998). Demography and diversity in organizations: A review of 40 years of research. Research in organizational behavior, 20, 77-140.

Yukl, G. (1998). Leadership in organizations (4th ed.). Upper Saddle River, NJ: Prentice-Hall. 